
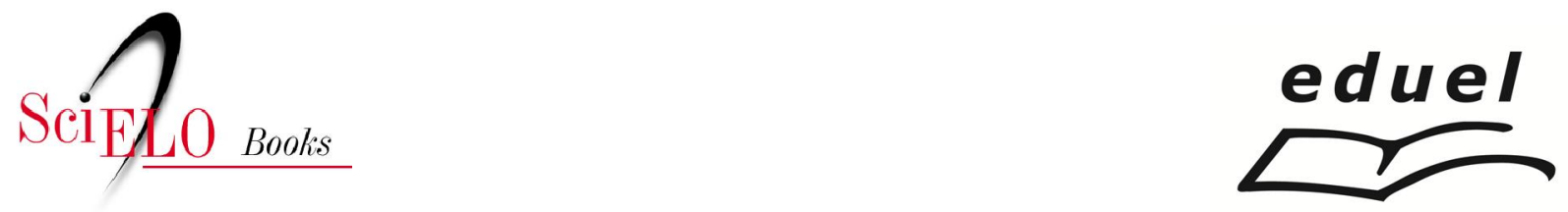

\title{
Vigilância epidemiológica
}

\author{
Regina Mitsuka-Breganó \\ Fabiana Maria Ruiz Lopes-Mori \\ Italmar Teodorico Navarro \\ (orgs.)
}

MITSUKA-BREGANÓ, R., LOPES-MORI, FMR., and NAVARRO, IT., orgs. Toxoplasmose adquirida na gestação e congênita: vigilância em saúde, diagnóstico, tratamento e condutas [online]. Londrina: EDUEL, 2010. Vigilância epidemiológica. pp. 48. ISBN 978-85-7216-676-8. Available from SciELO Books $<$ http://books.scielo.org $>$.

\section{(1) $(0)$}

All the contents of this work, except where otherwise noted, is licensed under a Creative Commons Attribution-Non Commercial-ShareAlike 3.0 Unported.

Todo o conteúdo deste trabalho, exceto quando houver ressalva, é publicado sob a licença Creative Commons Atribuição Uso Não Comercial - Partilha nos Mesmos Termos 3.0 Não adaptada.

Todo el contenido de esta obra, excepto donde se indique lo contrario, está bajo licencia de la licencia Creative Commons Reconocimento-NoComercial-CompartirIgual 3.0 Unported. 


\section{Vigilância epidemiológica}

Em 31 de agosto de 2010, o Ministério da Saúde aprovou a Portaria no. 2472, Art. 6, na qual inclui a toxoplasmose aguda gestacional e congênita na Lista de Notificação Compulsória em Unidades Sentinelas (LNCS). "Parágrafo único. As doenças e eventos constantes no Anexo III desta Portaria devem ser registrados no Sistema Nacional de Agravos de Notificação (SINAN), obedecendo às normas e rotinas estabelecidas para o Sistema". (BRASIL, 2010).

O município deve notificar os casos de toxoplasmose adquirida na gestação e congênita.

O instrumento de notificação será a "Ficha Individual de Notificação", definida pelo SINAN, preenchida pelo profissional da unidade básica de saúde local e notificada à Vigilância Epidemiológica da Secretaria Municipal de Saúde.

Compete à Vigilância Epidemiológica e à Vigilância Sanitária a investigação dos casos notificados, com a avaliação técnica pelo médico responsável pelo setor e apoio do laboratório de referência da Secretaria Municipal de Saúde. É imprescindível que esta ação seja compartilhada com a Vigilância Sanitária em função das necessárias ações de saúde ambiental (análise de água, alimentos, fiscalização de ambientes de manipulação de alimentos etc.).

Os casos confirmados de infecção ativa deverão ser tratados de acordo com os critérios técnicos já estabelecidos.

Criança com suspeita de infecção congênita deve ser encaminhada ao Ambulatório de Referência de Infectopediatria do Hospital de Clínicas da Universidade Estadual de Londrina para confirmação laboratorial e/ou tratamento. As gestantes deverão ser encaminhadas ao Ambulatório de Patologias Obstétricas do Hospital de Clínicas da Universidade Estadual de Londrina. 